Nathan Mastnjak

\title{
Deuteronomy and the Emergence of Textual Authority in Jeremiah
}

[Deuteronomium und die Entstehung von Textautorität in Jeremia.]

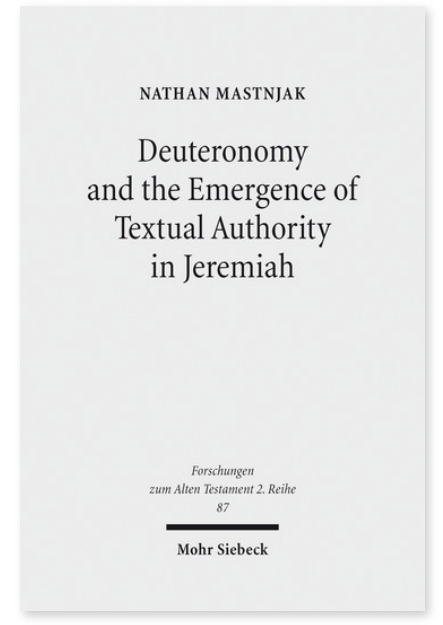

2016. XI, 261 Seiten. FAT II 87

ISBN 978-3-16-154402-6

DOI 10.1628/978-3-16-154402-6

eBook PDF 94,00€

ISBN 978-3-16-154401-9

fadengeheftete Broschur 94,00€
Veröffentlicht auf Englisch.

Die enge Beziehung zwischen Jeremia und Deuteronomium stand über ein Jahrhundert lang im Zentrum der JeremiaForschung. Nathan Mastnjak wirft ein neues Licht auf dieses Phänomen, indem er jede glaubwürdige Anspielung auf Deuteronomium in Jeremia einer genauen Untersuchung unterzieht und dabei besonderes Augenmerk auf Interpretationsprozesse und die Verschiebungen der Autorität legt. Indem er jede Anspielung in der Entstehungsgeschichte des Buchs lokalisiert, zeichnet der Autor eine merkliche Verschiebung der Wahrnehmung der deuteronomischen Quellen nach. Während frühe Texte in Jeremia auf Deuteronomium als lediglich einem angesehenen literarischen Werk unter vielen hinweisen, entwickelt es sich in späteren Abschnitten zu einer religiösen textlichen Autorität. Diese späteren Abschnitte erstellen und entfalten Deuteronomium als eine Autorität, werden aber zeitgleich daran gehindert, es im Interesse religiöser Neuerung umzuwandeln.

Nathan Mastnjak Born 1983; 2015 PhD, with honors, University of Chicago; currently Postdoctoral Fellow in Indiana University's Borns Jewish Studies Program.

Jetzt bestellen:

https://mohrsiebeck.com/buch/deuteronomy-and-the-emergence-of-textual-authority-in-jeremiah-9783161544026? no_cache $=1$

order@mohrsiebeck.com

Telefon: +49 (0)7071-923-17

Telefax: $+49(0) 7071-51104$ 